\title{
REFLEXÕES SOBRE A FORMAÇÃO DA DECISÃO JUDICIAL À LUZ DO REALISMO JURÍDICO
}

Victor Colucci Neto

\section{Resumo:}

Analisa-se o processo de formação da decisão judicial à luz do realismo jurídico, movimento desenvolvido nos Estados Unidos nas décadas de 1920 e 1930, frente à clássica ideia formalista de que os juízes seriam mero aplicados do direito ao caso concreto. Apresenta-se neste trabalho a abordagem da influência das preferências político-ideológicas ou pessoais do juiz no processo decisório, analisando modelos de comportamento judicial. Expõe-se ideia acerca da harmonização entre realismo e formalismo jurídico e o modelo dual de julgamento. A pesquisa ora desenvolvida visa refletir sobre o que realmente ocorre no processo de tomada de decisão judicial.

\section{Palavras-chave:}

teoria da decisão judicial; realismo jurídico; formalismo jurídico; intuição judicial; palpite.

\section{REFLECTIONS ON THE FORMATION OF THE JUDICIAL DECISION IN THE LIGHT OF LEGAL REALISM}

\begin{abstract}
:
The judicial decision-making process is analyzed in the light of legal realism, a movement developed in the United States in the 1920s and 1930s, in the face of the classic formalist idea that judges would merely apply the law to the concrete case. This paper discusses the influence of the political-ideological or personal preferences of the judge in the decisionmaking process, analyzing models of judicial behavior. An idea is presented about the harmonization between realism and legal formalism and the dual model of judgment. The research developed here aims to reflect on what actually occurs in the judicial decisionmaking process.
\end{abstract}

\section{Keywords:}

theory of judicial decision; legal realism; legal formalism; judicial intuition; hunch.

*Victor Colucci Neto, mestrando da Faculdade de Direito de Ribeirão Preto da Universidade de São Paulo, FDRP/USP, pós-graduação lato sensu em Direito Processual Civil pela UNAERP, advogado. E-mail para correspondência vitorcn@hotmail.com. 


\section{INTRODUÇÃO}

O presente artigo tem por objetivo analisar as influências dos fatores alheios ao direito no processo de formação da decisão judicial e discorrer sobre como os juízes realmente julgam, quais os principais elementos extrajurídicos influenciam a decisão judicial.

Debatem-se muito como as decisões devem ser tomadas, mas pouco de descrever como elas realmente ocorrem, resultando em teorias normativas distantes da realidade, idealizadas, que consideram os magistrados isoladamente sem considerar sua realidade de trabalho e as limitações como pessoa humana.

Neste estudo da Teoria da Decisão Judicial, analisa-se a teoria do Realismo Jurídico, desenvolvida nos Estados Unidos a partir das décadas de 1920 e 1930, em comparação com o Formalismo Jurídico.

O Juiz é um ser humano suscetível a atalhos mentais, heurísticas e vieses, bem como possui preferencias políticas, ideológicas e pessoais, de forma que o presente trabalho tem por escopo analisar com base na bibliografia e estudos empíricos publicados no meio acadêmico, quais seriam as possíveis influências desses fatores no processo de tomada da decisão judicial.

$\mathrm{O}$ ato de decidir pode decorrer de impulso refletido, estudado, ou de uma atividade rápida e instintiva, de forma que é relevante analisar neste artigo as peculiaridades de cada sistema, bem como a incidência dos palpites e das intuições no processo de decisão.

Ao final, com base em uma análise interdisciplinar do direito, psicologia e neurociência, busca-se compreender a realidade do processo de tomada de decisão judicial no sentido daquilo que realmente ocorre na prática, busca-se explicar a realidade desse processo de tomada da decisão judicial.

\section{Realismo Jurídico: em busca da explicação sobre como os juízes efetivamente julgam os casos.}

O Juiz é o profissional que dentre outras funções, diariamente, tem a missão de enfrentar processos e tomar decisões, algumas simples outras complexas, que resolvam 
questões que lhes são submetidas na busca da pacificação social com a aplicação do sistema jurídico ao caso concreto.

Mas como essa nobre e tão importante atividade é realizada? Como o Juiz decide os casos que lhes são submetidos? Os Juízes seriam formais aplicadores do Direito como um silogismo ou, como pessoa humana que é, estaria aberto a sofrer influências extrajurídicas, tais como da sua personalidade e ideologia, ou influências físicas, biológicas, políticas dentre outras?

No afã de responder a perguntas como estas e com a intenção de investigar o que ocorre na realidade do processo de formação da decisão judicial - não se contentando com a clássica explicação dos formalistas no sentido de que decisão seria decorrente da mera aplicação racional da lei ao caso concreto, surgiram os estudos do Realismo Jurídico, movimento questionador que se difundiu nos Estados Unidos principalmente entre 1920 e 1930.

O movimento realista não se baseia na simples negação do direito como erroneamente já se interpretou, mas em verdade, busca demonstrar que fatores externos ao direito de fato exercem influencia no resultado da decisão judicial, desenvolvendo-se como teoria da decisão judicial.

Para Llewellyn (1931), a indeterminação, mesmo a incoerência da lei significava que "a personalidade do juiz" deve, em algum grau, explicar os resultados do caso. Em sua opinião, "nosso governo não é um governo de leis, mas um governo das leis através dos homens".

Segundo explica TUMONIS (2012), uma importante contribuição do realismo jurídico foi estabelecer uma clara diferenciação entre a tomada de decisão real e a fundamentação apresentada na decisão judicial. Para os realistas, era perfeitamente natural que os juízes utilizassem regras formais para justificar suas decisões, ao invés de declarar que chegaram à decisão seguindo o palpite ou por causa de sua composição de personalidade e preferências pessoais ou análises políticas.

Sobre seu surgimento histórico, relevante destacar que entre os anos de 1930 e 1931, existiu intenso movimento de publicações e correspondências trocadas entre Karl Llewellyn, Roscoe Pound e Jerome Frank que culminou na criação do realismo.

NOJIRI e CESTARI (2015) explicam com maestria ter sido Karl Llewellyn o responsável por cunhar o termo "realismo", com seu artigo de 1930 A realistic Jurisprudence 
- the next step (LLEWELLIN, 1930) no Columbia Law Review. No mesmo ano, Jerome Frank publica seu renomado Law and the Modern Mind, em que emprega a psicologia principalmente behaviorismo - para interrelacioná-lo com o Direito. Frank considerou tão importante a psicologia que, ao invés de a ideia clássica de considerar Fato + Regra = Decisão, formulava Estímulo + Personalidade do Juiz = Decisão (LEITER, 2002, p. 9-10).

No ano seguinte, em 1931, Roscoe Pound, diretor da faculdade de direito de Harvard, respondeu criticamente com The Call for a Realist Jurisprudence, publicado no Harvard Law Review. Assim que se viram em uma 'disputa' academica, Llewellyn e Frank - apesar deste último não figurar formalmente como autor, escreveram, em 1931, Some Realism about Realism - Responding to Dean Pound. Esse aparente conflito academico foi superado, Pound elogiou o trabalho intelectual de Llewellin em correspondência enviada a este, bem como seguiram com intensiva troca de cartas por mais de duas décadas (NOJIRI e CESTARI, 2015).

TAMANHA (2008, p. 735), por sua vez, demonstra com profundidade que o realismo que se desenvolveu com mais intensidade a partir de 1930, já era anteriormente objeto de estudo e reflexão antes desse marco temporal.

Ultrapassada essa sumária análise histórica, relevante explicitar as bases teóricas relevantes dos realistas para o Direito que, em que pese não decorram de consenso dentre os realistas, representa a ideia predominante do movimento.

Existem diferentes visões dentro do realismo, sendo que cada autor que interpreta o movimento tenta fazer sua própria sistematização. Para Brian Leiter (2002), por exemplo, existe um núcleo duro do realismo (core claim) que é compartilhado entre todos os realistas. Para Leiter, este núcleo seria a indeterminação do Direito e da Racionalidade jurídica, o que faz significar que o direito não é o único fator levado em consideração para uma decisão judicial, mas também, não há descrença total em relação ao direito, tal como uma visão extremada poderia fazer crer.

Na sua interpretação do Realismo Jurídico, Brian Leiter (2002) apresenta uma classificação: Posição Descritiva do Realismo (como os juízes decidem) versus uma Posição Normativa do Realismo (como os juízes deveriam decidir). A posição descritiva é então subdividida em Ala Sociológica (Sociological Wing) e Ala Idiossincrática (Idyosyncratc Wing). Já a Posição Normativa é subdividida em Ala Protoposneriana (Holmes e Felix Cohen) e Ala do Quietismo Normativo (Llewellyn e Frank, no sentido de que seria perda de tempo 
dizer que os juízes deveriam fazer, haja vista que quem decide o que os juízes fazem são os próprios juízes, sendo inútil dizer a eles para fazê-lo de outra forma.).

Outro autor que analisa o aspecto teórico do Realismo Jurídico, Tamanha (TAMANHA, 2008) traz abordagem diferente, segundo a qual o realismo pode ser encarado sob seu aspecto cético (skeptical aspect), ou pelo aspecto rule-bound, e uma terceira visão balanceada do realismo (balanced sense), que seguem explicados na tabela que segue.

Tabela 1 - Síntese da classificação de Brian Tamanha (2008), elaborada baseado em NOJIRI e CESTARI (2015).

\begin{tabular}{|l|l|}
\hline \multicolumn{1}{|c|}{ Aspecto Cético } & $\begin{array}{l}\text { Aspecto Rule-Bound (o direito está preso } \\
\text { às regras) }\end{array}$ \\
$\begin{array}{l}\text { O Direito possui falas, limitações e abertura } \\
\text { interpetativa. Por essa razão, os juízes } \\
\text { algumas vezes tomam decisões manipulando } \\
\begin{array}{l}\text { as regras jurídicas, influenciados por sua jurídicas podem funcionar; os } \\
\text { própria visão moral e política, bem como por } \\
\text { motivos pessoais. }\end{array}\end{array}$ & $\begin{array}{l}\text { podem aplicar a lei. Há fatores } \\
\text { práticos, sociais e institucionais que forçam } \\
\text { os juízes a julgarem de acordo com a lei. } \\
\text { decisões baseada no direito. Esse aspecto, } \\
\text { entretanto, nunca é atingido de forma } \\
\text { perfeita. }\end{array}$ \\
\hline $\begin{array}{l}\text { Visão Balanceada: Uma visão realista deverá balancear esses dois aspectos. Assim, o } \\
\text { aspecto rule-bound pode funcionar de forma satisfatória, mas sempre tendo em vista os } \\
\text { desafios anunciados pelo aspecto cético. }\end{array}$ \\
\hline
\end{tabular}

Na esteira da análise do Realismo Teórico, em que pese não seja unanimidade dentre os realistas, conforme bem explicado por Nojiri e Cestari (2015) não se pode negar o instrumentalismo como essência do realismo jurídico, uma vez que se buscava entender as regras jurídicas em termos de suas consequências sociais no sentido de melhor compreender como o direito funciona no mundo real, bandeira que trouxe apelo ao movimento conforme descrito por Llewellyn em seu Some Realism about Realism: Responding to Dean Pound ${ }^{1}$.

Os realistas não pretenderam conceituar o que é o direito, mas apenas como funciona o direito. Elucida Tumonis (2012, p. 1366) que o Realismo foi a mais controversa e importante teoria sobre decisão judicial na história. A questão central que o realismo coloca, em relação a uma teoria sobre decisão judicial é se “As decisões se valem de raciocínios jurídicos? Até que

\footnotetext{
${ }^{1}$ Eles [os realistas] vêem as regras, a lei como meio para os fins; como apenas meio para fins; como tendo significado apenas na medida em que são meios para fins. Eles [realistas] suspeitam, com a lei se movendo devagar e a vida ao seu redor se movendo rapidamente, que alguma lei pode sair da vida. Esta é uma questão em primeira instância: o que a lei faz, para as pessoas ou pelas pessoas? Na segunda instância, trata-se de fins: o que devemos fazer para as pessoas ou por elas? (LLEWELLYN, 1931, p. 1223. Tradução nossa)
} 
medida? O modo como os fatos se apresentam não seria mais relevante para um juiz do que o modo como as regras jurídicas se apresentam?" Essa tensão, que pode ser denominada entre o formalismo (regras jurídicas) e o realismo (fatos) existe até os dias de hoje e qualquer discussão que prescinda de um dos dois elementos será incompleta (TUMONIS, 2012, p. 1362).

Para os realistas, segundo este autor, são duas as atividades que um juiz realiza ao julgar: primeiramente, antes mesmo de analisar as regras, os juízes já tomam uma decisão prévia a respeito do caso submetido a julgamento, com base em fatores não jurídicos, como concepção pessoal de justiça, ideologia, classe social das partes, dentre outros. Tomada a decisão, os juízes buscam no direito a fundamentação jurídica do que já decidiram. Estas duas etapas, podem ser realizadas inconscimentemente pelo julgador.

O desenvolvimento da pesquisa dos realistas, nas últimas décadas, deu origem ao chamado Novo Realismo Jurídico, que tem como característica distintiva que se baseia na confirmação empírica da efetiva existência de influências extrajurídicas na formação das decisões judiciais.

Uma característica distintiva do Novo Realismo Jurídico é o exame minucioso de casos relatados, a fim de compreender como a personalidade judiciária, entendida nas influências dos resultados legais e como as instituições legais restringem ou desencadeiam influências. Essas investigações representam um esforço para testar as alegações realistas (estilo antigo) sobre a indeterminação da lei, e para implementar a sua chamada para o estudo empírico de quão diferente os juízes decidem os casos respondendo ao "estímulo" de cada caso (MILES e SUNSTEIN, 2007).

$\mathrm{Na}$ esteira dessas pesquisas empíricas, um estudo recente testou e concluiu ser falsa a ideia de que seria relevante o que o juiz comeu no café da manhã, para a formação da decisão judicial. Segundo esse estudo realizado em Israel, não importaria o que ele comeu, mas quando ele comeu exerceria impacto relevante nas decisões. Pesquisadores israelenses analisaram cinquenta dias completos de julgamento por oito juízes acerca de liberdade condicional. Os requerentes da liberdade condicional eram palestinos e judeus que estavam na prisão e eram potencialmente elegíveis para a libertação antecipada. Os pesquisadores obtiveram o registro completo de cada caso, incluindo o tempo que cada decisão foi tomada, e eles foram capazes de traçar o resultado provável em cada posição ordinal ao longo do dia. 
O estudo demonstrou que os primeiros casos a entrarem na pauta de julgamento, logo após os julgadores tomarem o café da manhã, tinham maior probabilidade de receber liberdade condicional. Mas as chances declinavam drasticamente à medida que a manhã avançava, chegando perto de zero para os que tinham a má sorte de serem julgados pouco antes do intervalo de lanche dos juízes no final da manhã. Após esse lanche, as probabilidades de liberdade condicional voltavam a subir, para cerca de $60 \%$, mas diminuíam drasticamente de novo até o horário de almoço. Mesma história depois do almoço.

Pela pesquisa realizada acima descrita o determinante mais importante do futuro dessas pessoas foi o número de minutos desde que os juízes haviam comido pela última vez, o que evidencia que fatores extrajurídicos de alguma forma influenciam no processo de tomada da decisão judicial.

Os tópicos seguintes deste texto abordam com maior detalhamento a forma como ocorrem essas influências extrajurídicas na tomada de decisões que são objeto de estudo do realismo jurídico.

\section{Psicologia Moral e o Direito: Intuições e os impulsos da decisão}

Segue como normativamente implícito que o ato de julgar deva ser um ato eminentemente racional, todavia, palpite e intuição são componentes do ato decisório.

Pesquisas recentes em neurociência e psicologia têm perquirido sobre como a mente funciona e, para este trabalho, pertinente indagar qual seria o papel dos palpites e das intuições na formação da decisão judicial.

Diana Richards (RICHARDS, 1985) apresenta com base na neurociência e psicologia que nós somos programados para pensar de duas maneiras diferentes dependendo da tarefa mental que enfrentamos. O primeiro tipo de pensamento, chamado na literatura de Sistema 1 (S1) produz impressões e sentimentos sem esforço, fonte de crenças explícitas e escolhas deliberadas do Sistema 2 (S2). O Sistema 1 é aquele utilizado nas tarefas rotineiras, automáticas, sem ponderação mental, processo inconsciente e rápido, marca da nossa natureza animal e instintiva, processamento que se mostra extremamente útil para certas ocasiões e desaconselhável para outras. O Sistema 2 é o nosso pensamento lento, usa energia mental e exige atenção, reflexão, realiza comparação de argumentos opostos na memória de trabalho. 
Estudiosos da psicologia esclarecem o conceito de intuição como o "saber diretamente que o processamento das informações resulta de uma visão holística não consciente" (SINCLAIR, 378).

O uso de racionalidade limitada e heurística na decisão faz definir o palpite como "um julgamento intuitivo que aparece rapidamente em nossa consciência, e cujas razões subjacentes nós normalmente não temos consciência, mas mesmo assim, nos sentimos fortes o suficiente para agir" (Apud Gigerenzer, 2007, 156).

Um famoso relato do pressentimento judicial é trazido pelo Juiz Hutchenson (HUTCHESON, 1929), segundo o qual um palpite é "aquele flash intuitivo de compreensão que faz a conexão entre a questão e a decisão".

Essas definições trazem em comum a velocidade presumida, estrutura simples e ausência de consciência do processo intuitivo, com conscientização do seu resultado, como insights, um flash que ilumine a anterior escuridão da dúvida.

O palpite parece definir um produto mental resultado de um tipo S1 de pensamento, um resultado consciente de um processo inconsciente. A intuição, por seu turno, sempre envolve elementos racionais, embora possa ser influenciado ou confirmado por sentimentos e requer conhecimento e experiência passada (RICHARDS, 1985).

Esse modelo de intuição explica como os juízes, notadamente os de primeira instância, decidem os casos considerados fáceis.

A crescente e notória carga de trabalho no Judiciário exige que o Juiz seja um profissional eficiente e rápido, além da sua formação jurídica e humanista. Como ser humano, os juízes tem um sistema mental funcional S1/S2, de forma que sua mente está disposta a pensar rapidamente quando lidam com situações e tarefas familiares, ou seja, quando o julgador reconhece em um caso que está sendo julgado, características que o torna análogo a caso anterior já julgado, intuitivamente, aplica a mesma decisão.

Sobre este tema, segue transcrição em tradução nossa, da célebre 'confissão' feita pelo Juiz Hutchenson (HUTCHENSON, 1929), no seu artigo "O julgamento intuitivo: a função do palpite na decisão judicial"'2:

Eu sabia que "proposições gerais não decidem casos concretos. A decisão dependerá de uma intuição mais sutil do que qualquer premissa maior".

Então, depois de onze anos como juiz seguidos de dezoito como advogado, eu, tendo sido informado pela observação e experiência sobre o que vou afirmar, pensei que seria sábio e decoroso afirmar corajosamente que "olhando bem, com exatidão,

\footnotetext{
${ }^{2}$ The Judgient Intuitive: The Function Of The Hunch, In Judicial Decision
} 
pesquisando, inspecionando, revisado, reconhecido, lido e relido, virado e revirado, folheado e examinado as iniciais, contestações, provas, alegações, testemunhas, interrogatórios, embargos... e todos os outros doces e especiarias, tanto de um lado quanto de outro, como um bom juiz deve fazer, coloco as sacolas de uma das partes numa ponta da mesa e as sacolas de outra parte na outra ponta.

Dali em diante, "prosseguia de modo a resolver as obscuridades dessas variadas e contraditórias passagens do direito que são reivindicadas pelos litigantes e partes", assim como o juiz Bridlegoose fez, com uma diferença apenas. "Quando o assunto era mais simples, líquido e limpo, por assim dizer, quando havia poucas sacolas na mesa", e ele teria usado "um enorme, grande dado, bom e justo", eu decidia o caso mais ou menos improvisadamente e pela "regra do polegar". Entretanto, quando o caso era difícil ou confuso, e girava em torno de um fato ou direito tão pequeno quanto um fio de cabelo, ou seja, "quando havia muitas sacolas de um lado e de outro" e o juiz Bridlegoose teria usado seu "pequeno, minúsculo dado", eu, depois de vasculhar, todo material ao meu dispor, e pensando devidamente a respeito, dei azo a minha imaginação e, refletindo sobre a causa, esperei pelo sentimento, pelo "palpite" aquele lampejo intuitivo de compreensão que faz o salto conectivo entre a questão e a decisão, e nos pontos mais sombrios para os passos judiciais, lança luz por todo o caminho.

E mais, "para que não seja apedrejado" por essa confissão, deixe-me antecipar aos meus irmãos da Advocacia e da Magistratura, "minha prática é a mesma tal como em suas outras profissões". (tradução nossa)

Jonathan Haidt (HAIDT, 2012) vale-se das lições do Juiz Hutcheson, acima transcritas, em sua célebre Palestra, convertida em artigo, com título MORAL PSYCHOLOGY AND THE LAW: HOW INTUITIONS DRIVE REASONING, JUDGMENT, AND THE SEARCH FOR EVIDENCE (Psicologia Moral e a Lei: como intuições dirigem o raciocínio, julgamento e a busca por evidência), para explicar sobre ser uma grande ilusão acreditar que a racionalidade seja a única fonte de conhecimento sobre verdades éticas e descreve que no lugar do "delírio racionalista" na psicologia moral está havendo uma mudança do racionalismo para o intuicionismo, e que as intuições vêm em primeiro lugar, segundo o raciocínio estratégico.

Julgamento e justificação são processos separados. A intuição leva ao julgamento e então, o julgamento leva ao raciocínio, que fornece uma justificativa ou apologia para o julgamento (HAIDT, 2012).

Estudos na área da psicologia social ${ }^{3}$ demonstram a tendência geral de que o julgamento de uma pessoa influencie outras. Além disso, é mais fácil para as pessoas acreditar nos seus julgamentos iniciais do que contradizê-los, o que decorre do viés da confirmação. Ou seja, quando analisamos um caso, não procuramos provas dos dois lados e depois escolhemos o mais provável de ser verdadeiro, mas sim, começamos com um palpite inicial e em seguida partimos em busca de evidências para confirma-lo (HAIDT, 2012).

\footnotetext{
${ }^{3}$ Solomon Asch, Social Psychology (1987); Muzafer Sherif, The Psychology of Social Norms (1936).
} 
A presença da intuição na formação da decisão judicial traz implicações, tais como, influências estranhas e impróprias como mostra, por exemplo, o estudo empírico realizado em Israel, já mencionado no início deste artigo. Outra implicação é a possível ocorrência de conflitos de interesse.

Para ilustrar essa ideia de conflito, Haidt (HAIDT, 2012) narra que certa vez foi visitado em sua Universidade da Virgínia por uma representante da National Science Foundation, e que foram a um local próximo quando ele tentou, cordialmente, pagar um café para a visitante, ao que fora impedido sob a explicação de que as diretrizes federais a proibiam de aceitar, o que ele depois concluiu ser uma política sensata. Segue explicando que quem recebe presentes ou alguma espécie de agrado, favorecimento, tem a predisposição a julgar os pedidos com enfoque comprometido, tendente ao acolhimento da pretensão submetida. Essa constatação o fez explicitar sua preocupação com o sistema de eleições de magistrados realizado em alguns estados norte-americanos.

Demonstramos a evidencia do palpite na formação da decisão, mas, por outro lado, o raciocínio, que equivale a pensar de forma lenta, pelo Sistema 2, é essencial na criação de padrões, quando ainda não existem. A doutrina traz que jovens juízes, com menos experiência, tendem a preferir "deliberação cuidadosa porque eles sabem o suficiente para ser cautelosos e não o suficiente para serem intuitivos” (SINCLAIR, 2010, p. 382).

Restou bem demonstrado, portanto, que os juízes na condição de seres humanos estão sujeitos a decidir com base no lampejo intuitivo que exsurge após tomar conhecimento do caso posto a julgamento, de forma que devem ter uma compreensão adequada de si mesmos e de suas limitações na tarefa de aplicar o melhor direito ao caso concreto, o que justifica dizer que é importante a incorporação de mais psicologia no currículo dos cursos de Direito.

\section{Heurísticas e Vieses na formação da decisão judicial}

Juízes, embora sejam profissionais especializados na função de decidir, bem treinados e motivados no ofício, não só decidem com heurística como estão sujeitos a vieses cognitivos (HORTA e COSTA, 2017).

A realidade mostra que juízes trabalham sob pressão de tempo e sobrecarga de trabalho, o que estimula a dependência de atalhos cognitivos que podem iludir o julgamento. 
Heurística é um procedimento mental simples. É uma espécie de atalho cognitivo que ajuda a encontrar respostas adequadas, ainda que geralmente imperfeitas, para perguntas difíceis. A palavra vem da mesma raiz que heureca (KANEHMAN, trad. 2012, p. 127).

Viés cognitivo, também um atalho mental, é uma tendência de distorção de julgamento que ocorre em situações particulares, levando à distorção perceptual, julgamento pouco acurtado, interpretação ilógica, ou o que se chama de irracionalidade.

Daniel Kahneman, ganhador do prêmio Nobel por seu trabalho em Economia Comportamental (HORTA e COSTA, 2017), sintetiza no seu livro "Rápido e Devagar", pesquisa sobre decisões tomadas com heurísticas e vieses. Esses modelos partem da constatação que, longe de serem agentes racionais que pesam todos os aspectos de um caso antes de decidir como proceder, seres humanos possuem uma racionalidade limitada e tomam decisões em condições de premência de tempo, informação incompleta e recursos mentais escassos, decidindo cotidianamente com base em palpites e intuições, usando atalhos cognitivos.

A sujeição a atalhos cognitivos na decisão atinge profissionais com alta escolaridade, mesmo alertados acerca de sua existência, como certa inevitabilidade dos vieses, que seria comparável a ilusões de ótica, que também decorrem do sistema de organização da mente humana.

Juízes também seguem intuições, atalhos mentais, seguem no seu piloto automático para analisar casos. Por exemplo, ao fixar uma condenação a título de indenização, estão sujeitos ao efeito da "ancoragem", que pode ter sido fixada, por exemplo, no pedido inicial, ou mesmo no valor que a parte requerente eventualmente tenha afirmado aceitar para fins de acordo, em sessão de audiência de conciliação, instrução e julgamento.

Deve ser salientado, porém, que em geral a utilização de heurísticas é bastante útil, em que pese algumas vezes possa levar a erros graves e sistemáticos.

A heurística da representatividade consiste na tomada de decisões considerando crenças relativas à probabilidade de eventos incertos. Kahneman e Tversky ilustram essa forma de julgamento com o exemplo: "Steve é muito tímido e reservado, invariavelmente prestativo, mas com pouco interesse pelas pessoas, ou no mundo da realidade. Uma alma mansa e limpa, ele tem necessidade de ordem e estrutura, e uma paixão por detalhes". E seguem questionando: Como as pessoas avaliam a probabilidade de Steve estar empregado em uma profissão em particular de uma lista de possibilidades (por exemplo, agricultor, 
vendedor, piloto de avião, bibliotecário ou médico)? Como as pessoas ordenam essas ocupações do mais para o menos provável? Na heurística representativa, a probabilidade de que Steve seja um bibliotecário, por exemplo, é avaliada pelo grau em que é representativo ou similar ao estereótipo de um bibliotecário. De fato, pesquisas com problemas desse tipo mostraram que as pessoas escolhem as profissões pela probabilidade e pela similaridade exatamente da mesma forma. Esta abordagem do julgamento de probabilidade leva a sérios erros, porque a similaridade, ou representatividade, não é influenciada por vários fatores que devem afetar os julgamentos de probabilidade (KAHNEMAN e TVERSKY, 1974).

Na sequência, passemos analisar "Ajuste e Ancoragem" que também são heurísticas de julgamento. Explicam Kahneman e Tversky que em certas situações são feitas estimativas começando de um valor inicial que é ajustado para produzir a resposta final. $\mathrm{O}$ valor inicial, ou ponto de partida, pode ser sugerido pela formulação do problema, ou pode ser o resultado de um cálculo parcial. Em ambos os casos, os ajustes são tipicamente insuficientes, ou seja, diferentes pontos de obtenção produzem estimativas diferentes, que são tendenciosas em relação aos valores iniciais, fenômeno que é denominado ancoragem (KAHNEMAN e TVERSKY, 1974).

Relevante ainda dizer sobre o Viés da Confirmação já mencionado em tópico anterior. Trata-se da tendência que os sujeitos têm de buscar ativamente informações que estejam em consonância com suas crenças preconcebidas e de se sentirem satisfeitos em confirmá-las, ao passo que atribuem pouco peso e evitam se deparar com informações incoerentes com essas mesmas preconcepções. Ou seja, as pessoas tendem a buscar não algo como a "verdade", mas informações que confirmem o que já pensam, e as ajudem a manter as próprias convicções (HORTA e COSTA, 2017).

Horta e Costa (2017) narram que uma das formas de mitigar esses vieses nas decisões judiciais seria a polêmica proposta de adotar ferramentas de inteligência artificial na atividade judicante, discussão que já é realidade ante o avanço das novas tecnologias sobre empregos caracterizados pela atividade intelectual. Essa temática, contudo, não chega a ser o escopo do presente artigo, demanda uma reflexão mais aprofundada, sendo mencionada pela correlação ao tema exposto.

Embora a maioria dos juízes tente construir suas decisões usando fatos, evidências e critérios da lei limitadores de preconceitos pessoais e emoções, seguem constantemente influenciados pelas ilusões cognitivas aqui descritas. 
Em resumo, a dependência de heurísticas e a prevalência de vieses atinge leigos bem como profissionais altamente capacitados quando pensam intuitivamente e, em termos de decisões judiciais, os juízes devem empenhar-se para tornar seus julgamentos feitos com atalhos mentais compatíveis com o seu conhecimento jurídico sobre o assunto.

\section{Preferências político-ideológicas ou pessoais do julgador e sua influência na decisão}

"Modelos atitudinais" conceituam a decisão como uma manifestação de preferência política dos magistrados, que foram descritos por C. Herman Pritchett, no seu livro The Roosevelt Court, de 1948 (HORTA, 2016).

Essa análise decorre da realidade dos julgamentos percebida sem a visão formalista de que a atividade judicial estaria adstrita à aplicação da lei ao caso concreto posto a julgamento, abraçando o realismo jurídico para demonstrar existir fatores extrajurídicos, como políticosideológicos ou pessoais do julgador a influir no julgado.

Durante décadas os "modelos atitudinais" sustentaram que as posições pessoais dos juízes eram o fator determinante das decisões, no sentido de que os juízes desejavam imprimir seu modo de encarar as políticas ao proferirem seus votos e sentenças. O auge dos modelos atitudinais ocorreu entre as décadas de 1960 e 1990. Em 2002, com o livro The Supreme Court and the Attitudinal Model, de Jeffrey Segal Harold Spaeth, tem-se o ápice dos modelos atitudinais, tendo sido nessa época iniciada a crítica à ideia de que toda sentença ou voto seria a expressão de uma preferência individual, salientando que o juiz não era um ator isolado (HORTA, 2016).

Pesquisadores questionaram, mais atualmente, a simplificação dos modelos atitudinais e passaram a incorporar outros fatores extrajurídicos que influiriam na decisão além da sua própria ideologia, como a possibilidade de sua decisão ser reformada por recursos a tribunais superiores, chance de ser voto vencido na turma, ou mesmo uma derrota em disputa com o Poder Legislativo (EPSTEIN; LANDES; POSNER; 2013, p. 65-89; SUSTEIN, 2006).

Segundo nos relata Ricardo de Lins e Horta (HORTA, 2016), em um estudo realizado sobre os padrões de decisão de turmas de juízes da segunda instância federal nos Estados Unidos, mencionando Cass Sunstein (2006), com base em 6.408 decisões colegiadas e 19.224 votos individuais, demonstraram que a composição das turmas era uma variável altamente significativa no resultado dos acórdãos. Quando as turmas eram compostas por três juízes de 
mesma afiliação ideológica, observava-se o fenômeno de "polarização do grupo", o qual tendia a proferir acórdãos com posições mais radicais. Porém, a presença de um único juiz de afiliação política diversa era o suficiente para mitigar as posições dos dois outros.

Este exemplo explica a "aversão à divergência", já que discordar dos colegas pode ser extenuante, exigir votos mais longos e melhor fundamentados, além de poder gerar constrangimentos e tensão entre os componentes da turma, que geralmente trabalham juntos durante anos. Sendo assim, juízes, como quaisquer seres humanos, prefeririam conformar-se ao grupo e tenderiam a evitar disputas entre si.

Um modelo inicial de formulação do comportamento judicial está contido na já citada obra The Behavior of Federal Judges (EPSTEIN; LANDES; POSNER, 2013). Os autores propõem que se conceba a decisão em quatro níveis distintos. Em primeiro lugar, o da decisão individual, em que ideologia, aversão ao esforço, preferência pelo lazer, história pessoal, personalidade, etc., pesam. Em segundo lugar, que se tenha em consideração como os efeitos de decisão de grupo, tais como a composição e a dinâmica de turmas de tribunais, a aversão ao dissenso e o efeito de conformidade, influenciam a decisão judicial. Num terceiro âmbito, o modelo incorpora os efeitos hierárquicos entre as instâncias judiciais, em que as cortes superiores restringem a liberdade de ação dos juízes. Por fim, os autores destacam as interações entre o Judiciário e os outros Poderes.

Relevante informar, por fim, que as tonalidades ideológicas das decisões judiciais variam conforme a instância analisada, sendo maiores nas cortes superiores, e menos relevantes na primeira instância. Os autores analisados concluem que o grau de discricionariedade dos juízes não é meramente uma questão de preferência ideológica pessoal, mas deriva da estrutura hierárquica do Poder Judiciário, isto é, do seu desenho institucional (EPSTEIN; LANDES; POSNER, 2013, p. 385-395).

\section{Comportamento Judicial: Modelos Legalista, Ideológico e Estratégico.}

Merece ser trazida neste trabalho ante a direta pertinência do tema a menção à classificação do comportamento judicial realizada pela ilustre jurista Patrícia Perrone Campos Mello (MELLO, 2018), mediante observação dos modelos legalista, ideológico e estratégico, conforme explicação baseada no seu brilhante artigo "A vida como ela é: comportamento estratégico nas cortes". 
O modelo legalista consiste na primazia do Direito, em seu material jurídico ortodoxo, como principal fator explicativo das decisões judiciais e previsão das decisões dos casos concretos. Como é intuitivo, esse modelo é insuficiente para explicar o comportamento dos juízes em uma multiplicidade de casos comumente enfrentados em matéria constitucional, repleto de cláusulas abertas e pode ser insuficiente para o preenchimento de conceitos jurídicos indeterminados ou para a solução de conflitos entre princípios constitucionais.

Contudo, esse modelo legalista tem valor reconhecido, já que a solução de uma grande gama de casos que chegam às cortes constitucionais e supremas cortes pode ser explicada por meio dele. Trata-se, geralmente, de casos em que o texto constitucional é explícito acerca da solução, ou cuja questão de fundo geralmente já foi apreciada.

O modelo ideológico consiste na percepção de que a ideologia do magistrado é o fator determinante dos julgados e do comportamento judicial dos magistrados. A ideologia, no caso, é concebida de forma ampla, como o conjunto de valores e de ideias que integram a visão de mundo do magistrado. A partir desse conjunto, procura-se explicar ou até mesmo predizer como determinado juiz votará em um caso inédito e controvertido.

O desenvolvimento de estudos empíricos voltados a mensurar a participação da ideologia dos magistrados em seus processos decisórios foi muito favorecido pelo ambiente ideológico norte-americano, que é bipartido e polarizado entre os democratas e os republicanos, e suas respectivas divergências ideológicas, têm uma projeção muito clara em matéria constitucional. Os democratas são geralmente mais progressistas do ponto de vista da tutela de direitos fundamentais e mais favoráveis à intervenção do Estado na economia. Os republicanos são mais conservadores e, portanto, menos protetivos em matéria de direitos fundamentais e menos abertos à intervenção estatal.

Trazer essa metodologia utilizada pelo modelo de comportamento ideológico norteamericano (attitudinal model) para o sistema brasileiro é bastante difícil. Não há no Brasil o mesmo universo ideológico plenamente definido e com projeção em matéria constitucional. Tampouco parece possível antecipar o posicionamento de um ministro sobre determinado tema apenas com base nas inclinações ideológicas do presidente que o nomeou ou do partido do presidente.

Apesar disso, acredita-se que os achados do modelo ideológico são importantes para a compreensão do comportamento judicial também no Brasil. 
Com relação ao Supremo Tribunal Federal, diversos ministros já reconheceram a influência das suas visões de mundo sobre os votos que proferem. A título ilustrativo, quando de sua confirmação pelo Senado, o Ministro Marco Aurélio reconheceu expressamente: "Primeiro idealizo a solução mais justa. Só depois vou buscar apoio na lei”.

Nesta linha do julgamento ideológico, convém mencionar o voto proferido pelo saudoso Ministro Menezes Direito no julgamento de casos com pesquisas com células-tronco embrionárias pelo STF, na ADI n. 3510, Relatoria Min. Ayres Britto. As pesquisas com células-tronco envolviam o emprego de embriões não utilizados na fertilização in vitro, ensejando a sua destruição. A questão suscitava sentimentos conflitantes acerca da proteção do direito à vida, tendo contado com a atuação da Conferência Nacional dos Bispos do Brasil (CNBB), na condição de amicus curiae, contra a validade das pesquisas nessas condições. $\mathrm{O}$ Ministro Direito era um ministro sabidamente muito católico. Entretanto, tinha plena compreensão da importância de proferir, na hipótese, uma decisão que não impusesse a visão de mundo de um determinado grupo religioso e reconheceu isso em seu voto ${ }^{4}$. A despeito disso, a fundamentação da sua decisão aludia à sumas papais, a reflexões teológicas e filosóficas e ponderava que o direito à vida tinha relação com valores que "não se esgotam em um só segmento do conhecimento humano", o que imporia, a seu ver, uma abordagem interdisciplinar sobre o tema. Ao final, o Ministro Direito concluiu que as pesquisas com células-tronco seriam constitucionais apenas se fossem realizadas sem a destruição do embrião. Caso contrário, violariam o direito à vida ${ }^{5}$. A argumentação, tal como desenvolvida no voto, demonstrava a dificuldade de um juiz decidir casos difíceis isento de influência da sua compreensão de mundo, ainda argumentasse acerca da neutralidade.

\footnotetext{
${ }^{4}$ Relevante trecho do voto do Ministro Menezes Direito: "Neste julgamento, penso que deve ficar claro que não se trata aqui de buscar uma definição científica de determinado evento fazendo uma declaração de princípios de natureza religiosa, canônica. Não se pode pôr a questão sob esse ângulo. Trata-se, ao contrário, de decidir uma questão sob o ângulo jurídico, o que não afasta a necessidade de buscar perspectiva interdisciplinar considerando valores apropriados que não se esgotam em um só segmento do conhecimento humano. [...]. O que a Suprema Corte do Brasil está desafiando não é, portanto, uma questão religiosa. É uma questão jurídica, posta no plano da interpretação constitucional. A religião pertence à intimidade do ser do homem e todos nós devemos abrir nossos corações com humildade e grandeza para proclamar nossa fé no mais íntegro respeito moral pela pluralidade que é marca indissociável das sociedades livres. Tentar estabelecer a ideologização da ciência ou enxergar o obscurantismo nos que creem e defendem sua fé é indigno desse trânsito da história da humanidade. É por essa razão que devemos pôr com toda claridade que estamos julgando o alcance constitucional da proteção à vida e à dignidade da pessoa humana" (ADIn 3510, p. 237-239, grifos originais suprimidos).

${ }^{5}$ Trata-se de entendimento extremamente restritivo da realização das pesquisas, que possivelmente teria ensejado sua supressão, se houvesse prevalecido, já que o método voltado à extração das células-tronco sem a destruição dos embriões ainda não tinha tido sua viabilidade científica, eficácia e segurança comprovadas (ADI n. 3510, p. 289-290).
} 
O modelo estratégico concebe o processo decisório como o resultado da interação dos magistrados com múltiplas influências, tais como: as suas próprias preferências, as preferências dos seus colegas de colegiado, os demais Poderes e a opinião pública.

O estudo do comportamento estratégico interno consiste na compreensão da interação entre juízes de um mesmo órgão colegiado, no qual, cada juiz depende da adesão da maioria para fazer o seu entendimento prevalecer. O juiz agirá estrategicamente quando puder antecipar como votarão os demais e formular seu voto de modo a capitanear tal maioria, sacrificando o encaminhamento que considera ideal, para defender a decisão mais próxima das suas preferências que seja capaz de obter o apoio dos demais (second best decision).

O estudo do comportamento estratégico externo se funda na interação entre as cortes e/ou entre os seus membros e instituições e agentes que lhes são externos, dentre os quais: o Poder Executivo, o Poder Legislativo e a opinião pública. O Poder Judiciário e seus membros são cercados de garantias cujo propósito é assegurar a independência das suas decisões. Contudo, em algumas circunstâncias, as cortes podem ser sensíveis a como certos agentes responderão a seus julgados e, se forem capazes de prever uma grande reação negativa a eles, possivelmente moderarão seus entendimentos de forma a minimizá-las.

A atuação estratégica, no que respeita ao procedimento, pode ter o propósito de evitar o julgamento de casos de baixa relevância, de forma a gerir o volume de feitos recebidos pela Corte. A atuação estratégica procedimental pode, ainda, se traduzir na tentativa de postergar ou de obstar o julgamento de um recurso, com base em argumentos processuais, quando o magistrado acreditar que o caso terá um desfecho divergente das suas preferências. Já o comportamento estratégico em decisões substantivas, leva o juiz a moderar seus entendimentos ou a optar por uma decisão que acomode suas preferências à necessidade de obter a adesão da maioria do colegiado, ou, ainda, que evite embates com o Executivo, com o Legislativo ou com a opinião pública.

No que respeita à atuação estratégica com base em decisões procedimentais, normas que regulam a admissibilidade dos recursos extraordinários preveem a exigência de diversos requisitos de admissibilidade. Trata-se de requisitos que foram construídos pelo que se convencionou chamar jurisprudência defensiva do STF, cumprindo a função de conter o volume de casos que chega à Corte e de produzir um filtro sobre seu acervo de processos.

O requisito da repercussão geral pode igualmente dar margem a comportamentos estratégicos. De acordo com o novo Código de Processo Civil, considera-se presente a 
repercussão geral quando a questão constitucional veiculada por meio de recurso extraordinário for relevante do ponto de vista econômico, político, social ou jurídico, e seu julgamento, por essa razão, ultrapassar os interesses subjetivos do processo, sendo sua demonstração condição de procedibilidade do recurso. Todavia, essa noção de repercussão geral constitui um conceito jurídico indeterminado no qual o alcance do conceito se sujeita à discussão. A sua aferição comporta alguma discrição e abre margem para a atuação defensiva da Corte, de forma a limitar o volume de recursos que chegam a ela.

Outro exemplo de instrumento de atuação estratégica, cujo uso tem sido bastante criticado, são os pedidos de vista interruptivos das sessões de julgamento. O regimento interno do Tribunal prevê a possibilidade e estabelece a devolução do processo, para prosseguimento da votação, até a segunda sessão ordinária subsequente ${ }^{6}$. Na prática, contudo, os pedidos de vista podem se alongar por muitos meses, até anos, e eventualmente obstar a conclusão de julgamentos com os quais o ministro que requereu a vista não concorda ${ }^{7}$.

Deve ser ponderado que as condutas indicadas acima como estratégicas, também poderiam ser sinceras. A dificuldade de comprovação do modelo estratégico consiste na multiplicidade de interpretações concorrentes para um mesmo evento, e o fato de as explicações serem produzidas a posteriori e, portanto, de serem tendenciosamente confirmadoras da hipótese com que trabalha o intérprete. A certeza acerca do comportamento estratégico é, nessa medida, de difícil obtenção. A despeito da dificuldade de comprovação empírica, o modelo joga luz e favorece a compreensão do comportamento das cortes em geral e do Supremo em particular.

\section{Processo dual de julgamento e a harmonização entre realismo e formalismo jurídico.}

Como visto neste trabalho, em contraponto aos formalistas que consideram a decisão judicial como resultado da mecânica aplicação da lei ao caso concreto, o movimento do realismo jurídico teve por escopo demonstrar que esse modelo idealizado de julgamento está distante da realidade e que o juiz é influenciado por outros fatores além do direito, realizam

\footnotetext{
${ }^{6}$ RISTF, art. 134.

${ }^{7}$ Para um levantamento sobre a longa duração dos pedidos de vista, v. FALCÃO, Joaquim; HARTMANN, Ivar A.; CHAVES, Vitor P. III Relatório Supremo em números: o Supremo e o tempo. Rio de Janeiro: Escola de Direito do Rio de Janeiro da Fundação Getúlio Vargas, 2014. p. 89-100.
} 
processo intuitivo com posterior raciocínio deliberativo no exercício do seu ofício de decidir os casos.

Contudo, de grande relevância a pesquisa desenvolvida no sentido de que os modelos do realismo e do formalismo não devem ser vistos como excludentes na definição do modo como os juízes criam suas decisões, mas sim, ambos possuem pontos que podem ser compatibilizados com os seus principais insights na formação do núcleo de um modelo preciso. Essa doutrina denomina esse modelo de julgamento como "anulação intuitiva" ou "formalismo realista" (GUTHRIE, RACHLINSKI e WISTRICH, 2007).

Referido movimento da anulação intuitiva ou formalismo realista, se apoia na psicologia contemporânea, pesquisas da mente humana e realizou pesquisas empíricas com juízes, consistente em testes de reflexão cognitiva, e postula que os juízes geralmente tomam decisões intuitivas, mas em certas decisões sobrepõem sua intuição com deliberação.

Esse modelo ora exposto é "realista", já que reconhece a fundamental importância do palpite e intuição na tomada de decisão, mas também é "formalista", ao passo que reconhece a importância da deliberação em restringir a inevitável influência da intuição.

Essa ideia de compatibilização dos conceitos proposta pela doutrina (GUTHRIE, RACHLINSKI e WISTRICH, 2007) desenvolve o modelo dual de julgamento, distinguindo a presença da intuição e da dedução para a conclusão das coisas. Esse modelo dual proposto foi baseado em um modelo desenvolvido por Daniel Kahneman e Shane Frederick, e postula que juízes fazem julgamentos intuitivos iniciais (Sistema 1), que eles podem (ou não) anular com deliberação. Como Kahneman e Frederick explicam: "O Sistema 1 rapidamente propõe respostas intuitivas a problemas de julgamento à medida que surgem, e o Sistema 2 monitora a qualidade dessas propostas, as quais podem endossar, corrigir ou substituir. Os julgamentos que são eventualmente expressos são chamados de intuitivos, se retiverem a proposta inicial hipotética sem muita modificação."

Esses modelos de dualprocess encontram apoio da psicologia evolutiva e da neuropsicologia. O cérebro consiste em sistemas sobrepostos, cada um dos quais desenvolvidos em um ponto diferente no passado evolutivo humano. Estudos da função cerebral revelam que as pessoas usam diferentes partes do cérebro para diferentes tipos de decisões. Exames de ressonância magnética do cérebro revelam que os lobos pré-frontais são mais ativos quando as pessoas tomam decisões deliberativas. Por outro lado, os lobos temporais laterais, a amígdala e os gânglios da base estão ativos durante o pensamento 
intuitivo e reflexivo, demonstrando essa evidencia de uso de diferentes partes do cérebro a depender do tipo de decisão.

Em conclusão, não consideramos os juízes nem como os tomadores de decisão puramente dedutivos imaginados pelos formalistas nem como os racionalizadores intuitivos imaginados pelos primeiros realistas, mas sim como pessoas que, apesar de serem profissionais da decisão, são humanos que tendem a tomar decisões intuitivas do Sistema 1, mas que podem anular suas reações intuitivas com um pensamento complexo e deliberativo.

\section{CONCLUSÃO}

Conforme pudemos demonstrar no decorrer do presente trabalho a decisão judicial não é fruto de um simples silogismo, de se aplicar a lei ao caso sob julgamento, e o movimento do realismo jurídico demonstra a realidade das decisões judiciais, dissociando-se da ilusão de que seriam decorrentes exclusivamente da racionalidade do julgador.

$\mathrm{Na}$ esteira do pensamento realista, os juízes não raciocinam com base nas regras abstratas, mas, ao se depararem com questões para serem julgadas têm antes um lampejo intuitivo, bem como estão sujeitos a serem influenciados por fatores extralegais, heurísticas e vieses, que podem em certos casos, conduzir a conclusões equivocadas.

O direito é invocado após o lampejo, ou seja, após a decisão já ter surgido para o julgador, mas na fundamentação escrita é demonstrada uma postura de dedução racional que não contempla toda a complexidade e realidade do processo decisório.

A conclusão intuitiva bem como a deliberação e confirmação jurídica da decisão são elementos essenciais do processo decisório, portanto, conclui-se que não se deve considerar os formalistas jurídicos e o movimento do realismo jurídico de forma estanque ou radicalmente opostos, pois ambos contribuem para a pesquisa de se tentar conhecer como realmente os juízes decidem os casos que lhes são submetidos, na esteira da contribuição que este trabalho procurou apresentar.

\section{REFERÊNCIAS}

CESTARI, Roberto; NOJIRI, Sérgio. Intepretações históricas e teóricas do Realismo Jurídico. XXIV Encontro Nacional do CONPEDI - UFS, Teorias da Decisão e Realismo Jurídico, p. 142-166, 2015. 
EPSTEIN, Lee; LANDES, William M.; POSNER, Richard A. The behavior of federal judges: a theoretical and empirical study of rational choice. Cambridge: Harvard University Press, 2013.

Gigerenzer, Gerd, and Henry Brighton, 'Can Hunches Be Rational', Journal of Law, Economics \& Policy, 4 (2007), 155.

GUTHRIE, Chris; RACHLINSKI, Jeffrey J.; WISTRICH, Andrew J. Blinking on the bench: how judges decide cases. Cornell Law Review. 2007, v. 93, p. 1-43.

HAIDT, Jonathan, in Moral Psychology And The Law: How Intuitions Drive Reasoning, Judgment, and The Serach For Evidence. 2012.

HORTA, Ricardo de Lins; COSTA, Alexandre Araújo. Das Teorias da Interpretação à Teoria da Decisão: Por uma Perspectiva Realista Acerca das Influências e Constrangimentos Sobre a Atividade Judicial. R. Opin. Jur., Fortaleza, ano 15, n. 20, p. 271-297, jan./jun. 2017.

HUTCHESON JR., Joseph C., Judgment Intuitive: The Function of the "Hunch" in Judicial Decision, 1929 , p. 274-288.

KAHNEMAN, Daniel; TVERSKY, Amos. Judgment under Uncertainty: Heuristics and Biases. Science, New Series, Vol. 185, No. 4157. (Sep. 27, 1974), pp. 1124-1131.

KAHNEMAN, Daniel; FREDERICK, Shane. A model of heuristic judgment. The Cambridge handbook of thinking and reasoning. Cambridge: Cambridge University Press, p. 267-293, 2005.

KAHNEMAN, Daniel. Rápido e devagar: duas formas de pensar. Trad. Cássio de Arantes Leite. Rio de Janeiro: Objetiva, 2012.

LEITER, Brian. American legal realism. U of Texas Law, Public Law Research Paper, n. 042, 2002.

LLEWELLYN, Karl N. Some realism about realism: Responding to Dean Pound. Harvard Law Review, v. 1, p. 1222-1264, 1931.

MELLO, Marco Aurélio. Competência: palavra que melhor resume o nosso Ministro do Supremo Tribunal Federal. Jornal da Cidade, Sergipe, 7 out. 2003. Suplemento especial.

MELLO, Patrícia Perrone Campos, em "A vida como ela é": comportamento estratégico nas cortes. Publicado na Revista Brasileira de Políticas Públicas. Vol. 08. N.², Ag. 2018.Disponível em: https://www.publicacoesacademicas.uniceub.br/RBPP/article/view/5481/pdf

MILES, Thomas J. and SUNSTEIN, Cass R. The New Legal Realism. December 2007.

RICHARDS, Diana. When Judges Have a Hunch - Intuition (and Some Emotion) in Judicial Decision-Making, p. 01-16, 1985.

SUSTEIN, Cass R. Moral Heuristics. The Las School The University Of Chicago, 2003.

SUNSTEIN, Cass et al. Are Judges Political?: An Empirical Analysis of the Federal Judiciary. Washington: Brookings Institution Press, 2006.

SINCLAIR, Marta, 'Misconceptions About Intuition', Psychological Inquiry, 21 (2010), 378-386. 
TAMANHA, Brian Z. Legal Realism in Context. Washington University in St. Louis School of Law. [S.l: s.n.], 2014.

TUMONIS, Vitalius. "Legal Realism \& Judicial Decision-Making”, Jurisprudence, v. 19, n. 4, p. 1361-1382, 2012. 